Research Article

\title{
Combined Effects of Graphite Tailings and Curing Conditions on the Early-Age Performances of Cement Mortar
}

\author{
Hongbo Liu, ${ }^{1}$ Yuxin Zhang, ${ }^{1}$ Ben Li $\mathbb{D}^{2},{ }^{2}$ and Zhongrui Wang $\mathbb{D}^{1}$ \\ ${ }^{1}$ School of Civil Engineering, Heilongjiang University, Harbin 150080, China \\ ${ }^{2}$ Advanced and Sustainable Infrastructure Materials Group, School of Transportation, Civil Engineering and Architecture, \\ Foshan University, Foshan, Guangdong 528000, China
}

Correspondence should be addressed to Ben Li; hlju417@163.com and Zhongrui Wang; wzrice@163.com

Received 17 December 2019; Revised 2 April 2020; Accepted 19 May 2020; Published 14 August 2020

Academic Editor: José Aguiar

Copyright (C) 2020 Hongbo Liu et al. This is an open access article distributed under the Creative Commons Attribution License, which permits unrestricted use, distribution, and reproduction in any medium, provided the original work is properly cited.

\begin{abstract}
In this study, the combined effects of different amounts of graphite tailings (GT) as a substitute for sand and three cure methods on the early-age mechanical and material performances of cement mortar have been investigated. The results can be concluded that graphite tailings and hot-water cure method can effectively improve the early strength of cement-based materials and facilitate the formation of high-density calcium silicate hydrate $(\mathrm{C}-\mathrm{S}-\mathrm{H})$, more $\mathrm{Ca}(\mathrm{OH})_{2}(\mathrm{CH})$, and other hydration products. Simultaneously, the pore structure distribution in the cement mortar is improved to be finer. Finally, this paper explains the mechanism of GT and hot-water curing (HWC) method on early-age performances of the cement mortar through the graphic model and provides the basis for selecting the GT and HWC method on improving early performance requirements for special engineering or rapid repair engineering through the proposed comprehensive quantitative calculation model.
\end{abstract}

\section{Introduction}

Cement-based materials are the most widely used building materials worldwide. In recent decades, the composition and characteristics of cements, such as the hydration process, mechanical properties, durability, workability, material properties, pore structures, and C-S-H content, have been extensively studied from a physical and chemical perspective [1-3]. Of the various properties, early performance is of increasing interest. Research on the early strength of cement-based materials is important for several reasons [4-8]: (1) increasing the early strength can shorten the construction period and accelerate the use of building formwork or improve the use of the formwork, which is conducive to the economic sustainability of building construction projects. (2) For major engineering or military engineering applications, early-strength cement-based materials can meet engineering service conditions or military requirements. (3) Early-strength cement-based materials are of great significance for the repair, reinforcement, and renewal of airport runways, expressways, ports, and terminals. (4) The study of the early strength property also provides a basis and support for high-strength concrete, high-performance concrete, or ultrahigh-strength concrete. The work was driven by the military, important projects, mass production, and industrialization requirements for building materials to be ready rapidly and in an economical way. The performance of cement-based materials at an early time and their immediate use are the result of scientific research, engineering needs, and the industry developments [9-12].

The early quality of cement-based materials depends mainly on the composition and the curing conditions [13]. There are several methods to obtain early strength in concrete or cement mortar. One effective way is to change the curing method, such as using a hot-water curing method, boiling-water curing method, autogenous curing method, changed hot-water curing method, microwave curing method, accelerated curing method, and combination curing method (traditional method with the accelerated curing method or other methods) [14-18]. The accelerated 
curing methods that are applied during actual engineering applications are very limited [19]. Furthermore, some curing methods, such as boiling-water curing or autogenous curing without effective hydration, can result in significant disadvantages. For example, the compactness and workability of cement-based materials can be adversely impacted, inhomogeneous hydrate products can be formed, and the heterogeneity of the material matrix can be increased, which affect the pore structure distribution and crack density, resulting in a decreased comprehensive performance. Therefore, on the basis of changing the curing method, the aforementioned deficiencies can be addressed by using fine materials, such as an admixture, a cementitious material, or a fine aggregate, such as silica fume, fly ash, steel slag, or tailings. Fine materials can not only improve the early performance of cement-based materials but also contribute to green development through the reuse of solid waste and reduction in the consumption of construction raw materials [20-30]. These benefits collectively contribute to sustainability and economic development of green building projects.

Graphite tailings (GT) are a new type of tailing that are a $\mathrm{Ca}-\mathrm{Si}-\mathrm{Fe}-\mathrm{Al}$ ceramic material with sufficient $\mathrm{SiO}_{2}$ and a certain amount of calcium, iron, and aluminum oxide; it is a constituent of concrete, either as an aggregate or as a cementing material, or both $[31,32]$. The decreased fineness modulus and increased water absorption or water retention rate of graphite tailings can improve the performance of construction materials by replacing sand as a fine aggregate. Although some published studies on building materials containing GT have evaluated their suitability and mechanistic performance improvement or mesostructure changes, research on changing the properties of cement-based materials with GT is still in its infancy. In particular, there have been no studies conducted with a focus on the effects of incorporating GT in concrete or cement mortar for increased early strength and associated curing methods that would enable rapid construction and efficient structural use. The goal of this study is to fill these research gaps by investigating the early strength and material characteristics of cement mortar that incorporates GT as a replacement for sand as a fine aggregate and is subjected to different curing conditions. Flexural and compressive strength were measured to evaluate the impact of the GT on the macroperformance, material morphology, hydration products, and pore structure; the functional groups were investigated to determine the mesoscopic properties during different curing schemes. Finally, a schematic model was used to explain the mechanism of the impact of GT on the early performance of cement-based materials. Simultaneously, the optimal curing method and the amount of GT are also proposed in this paper to quantify the impact of GT and curing methods on cement-based materials, special engineering, or rapid repair engineering.

\section{Materials and Experimental Methods}

The experimental plan is shown in Figure 1, and the test details are as follows.

\subsection{Materials}

2.1.1. Raw Materials and Mixing Proportions. Ordinary Portland cement (P.O 42.5), local river sand with a fineness modulus of 2.3 , GT with a fineness modulus of 0.9 , and groundwater were used throughout the experiments. The graphite tailings used in this study were from Jixi, China (longitude $130^{\circ} 24^{\prime} 24^{\prime \prime}$, north latitude $44^{\circ} 51^{\prime} 12^{\prime \prime}$ ). The apparent comparison of GT and river sand is shown in Figure 2. The laser particle size distribution and granular gradation of the GT and sand are shown in Figure 3. Tables 1-3 list the mechanical properties of the cement, the chemical properties of the cement, sand, and graphite tailings, and the mineral content of cement and graphite tailings, respectively. The physical properties of river sand and graphite tailings are listed in Table 4 . In summary, the physical and chemical properties of GT and sand are similar, and its appearance is similar to sand. The main minerals (mass content) in GT are quartz $(79.7 \%)$, clay $(7.4 \%)$, biotite $(8.6 \%)$, graphite $(0.02 \%)$, and others. The content of graphite in the GT was $0.02 \%$ by mass, and GT was only determined through a sieve. At the same time, by comparing its apparent morphology, physical and chemical properties, harmful components, etc., GT can be regarded as thin, nonpolluting, and pollution-free sand that can be used as a building material.

In this study, the graphite tailings replaced river sand in different volume ratios, such as $0-40 \%$, the water-to-cement ratio $(\mathrm{w} / \mathrm{c})$ was 0.4 , and the blinder-to-sand ratio $(\mathrm{b} / \mathrm{s})$ was 1.5. The mixing proportions of the graphite tailing-cement mortar (GTCM) specimens are listed in Table 5, and slump of all the test specimens meet the requirements of the building materials.

\subsubsection{Specimen Casting and Curing Conditions. The GTCM} specimens had dimensions of $40 \mathrm{~mm} \times 40 \mathrm{~mm} \times 160 \mathrm{~mm}$ and were demolded after $24 \mathrm{~h}$ in accordance with the Chinese standard GB/T 17671-1999 [33]. The curing schemes are listed in Table 6. The standard curing method (SC method) is performed in a steam curing room with a temperature of $20 \pm 2^{\circ} \mathrm{C}$ and a relative humidity of $95 \%$, and the hot-water curing method (HWC method) is performed in a water bath apparatus (HH-F). The combination curing method (CC method) includes the aforementioned two methods as follows. (1) For 1 day, the demolded specimens were cured in a steam curing room for $12 \mathrm{~h}$ and in a water bath apparatus for $12 \mathrm{~h}$ at $60^{\circ} \mathrm{C}$. (2) For 3 days, there are two methods. The first method involved the demolded specimens being cured in a steam curing room for 1 day and in a water bath apparatus for 2 days at $60^{\circ} \mathrm{C}$ (CC: 1-2). The other method involved the demolded specimens being cured in a steam curing room for 2 days and in a water bath apparatus for 1 day at $60^{\circ} \mathrm{C}$ (CC: $\left.2-1\right)$.

\subsection{Experimental Methods}

2.2.1. Mechanical Property Test. A total of 400 GTCM specimens were prepared for the compressive and flexural strength tests using a cement mortar flexural and 


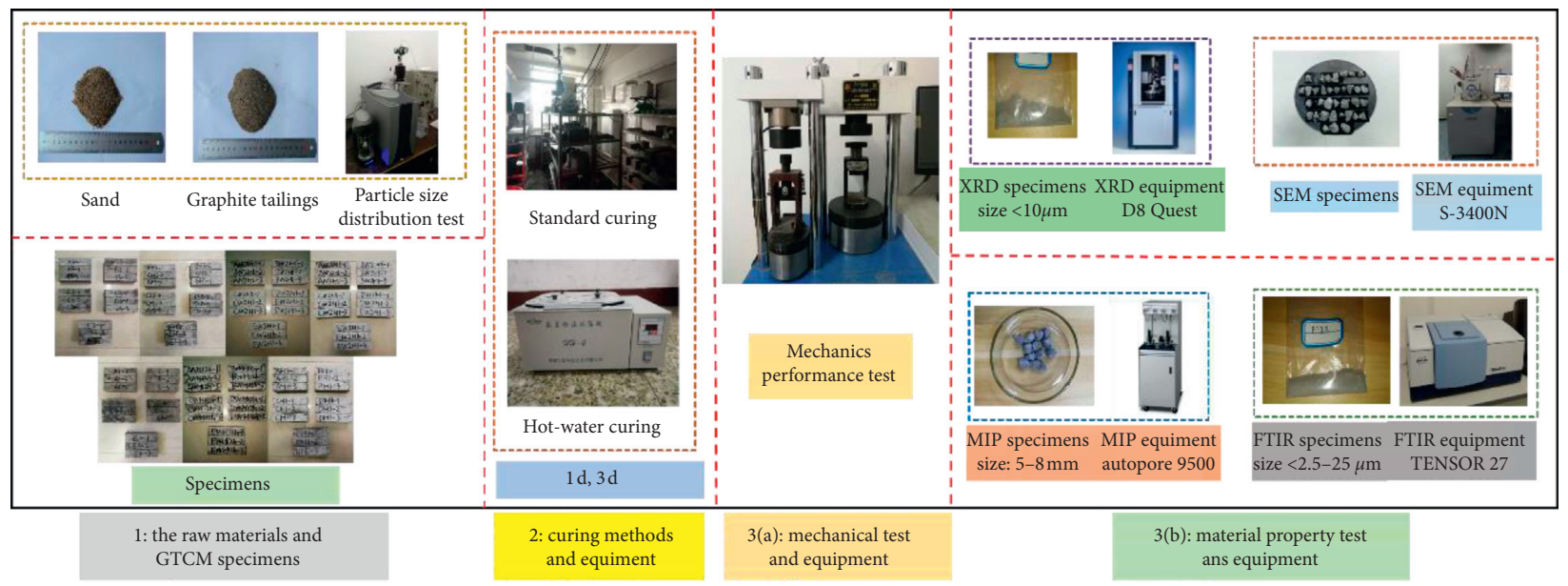

FIGURE 1: Flowchart of experimental methods.

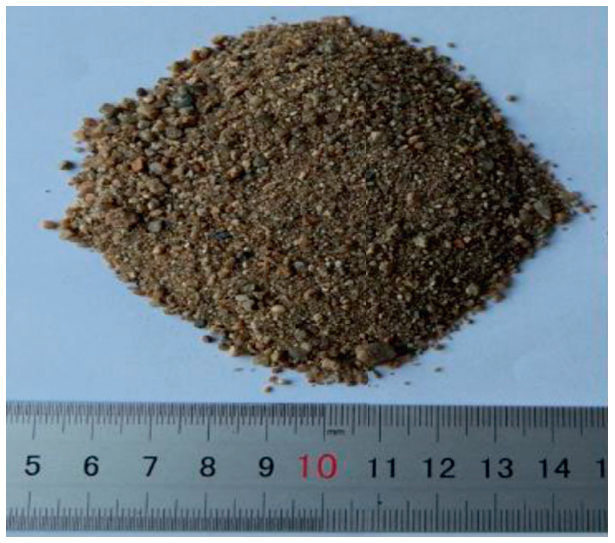

Sand

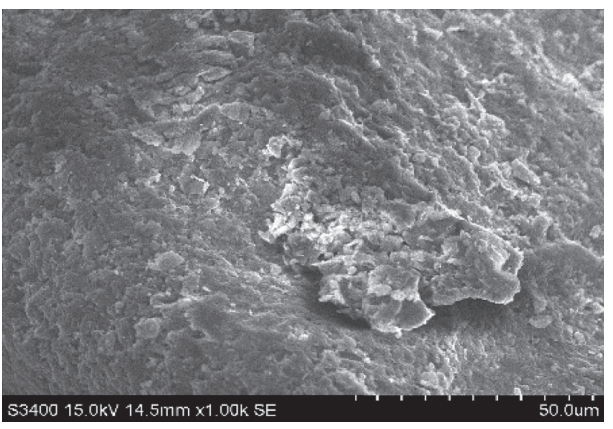

Sand

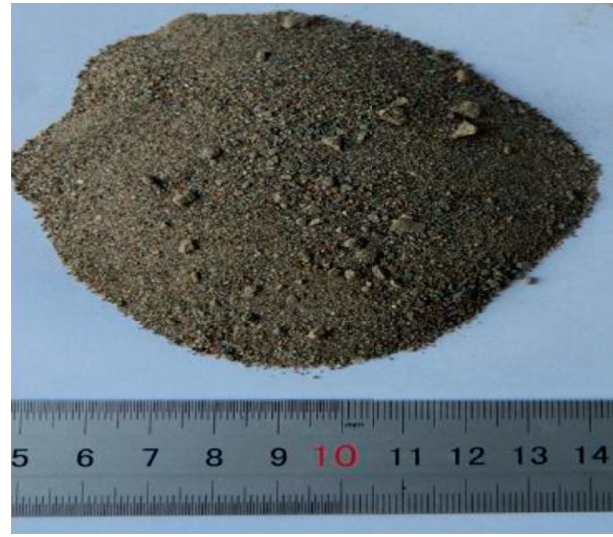

GT

(a)

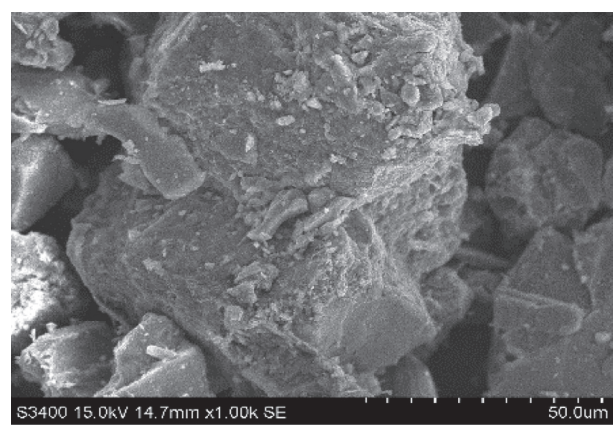

GT

(b)

FIGURE 2: The apparent comparison of GT and sand: (a) apparent comparison; (b) SEM comparison.

compressive constant stress testing machine (HYE-300B) according to JTG E30-2005 [36].

2.2.2. Material Characterization Tests. To further explore the effect of the GT on the early performance of cement mortar under the action of different curing conditions, several experimental methods were applied. Sixty samples were subjected to mercury intrusion porosimetry (MIP), scanning electron microscopy (SEM), X-ray diffraction (XRD), and Fourier-transform infrared spectroscopy (FTIR) to analyze the changes in the pore structure distribution, mesomorphology, hydration products, and chemical bonding or molecules in the GTCM specimens subjected to 


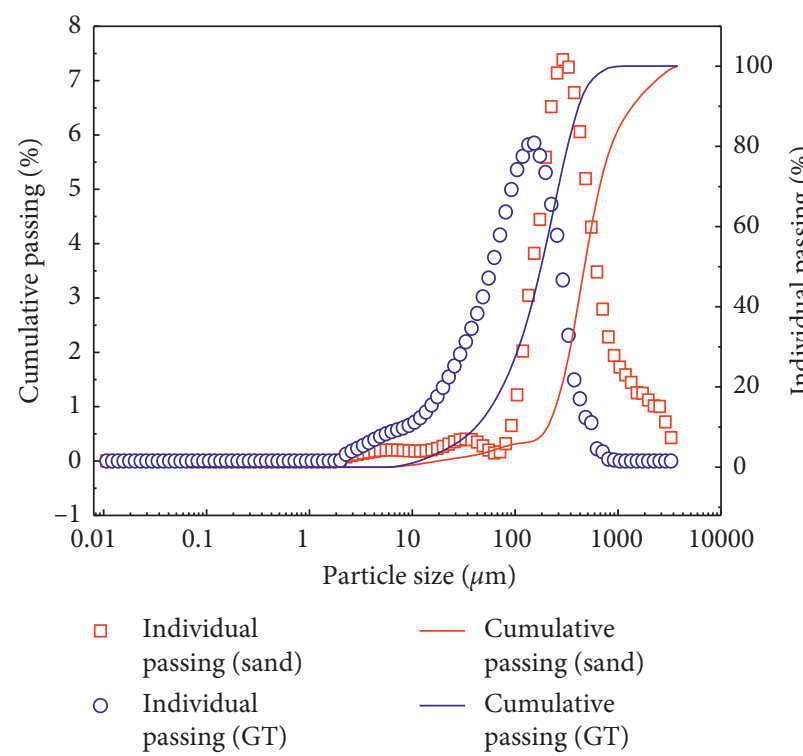

(a)

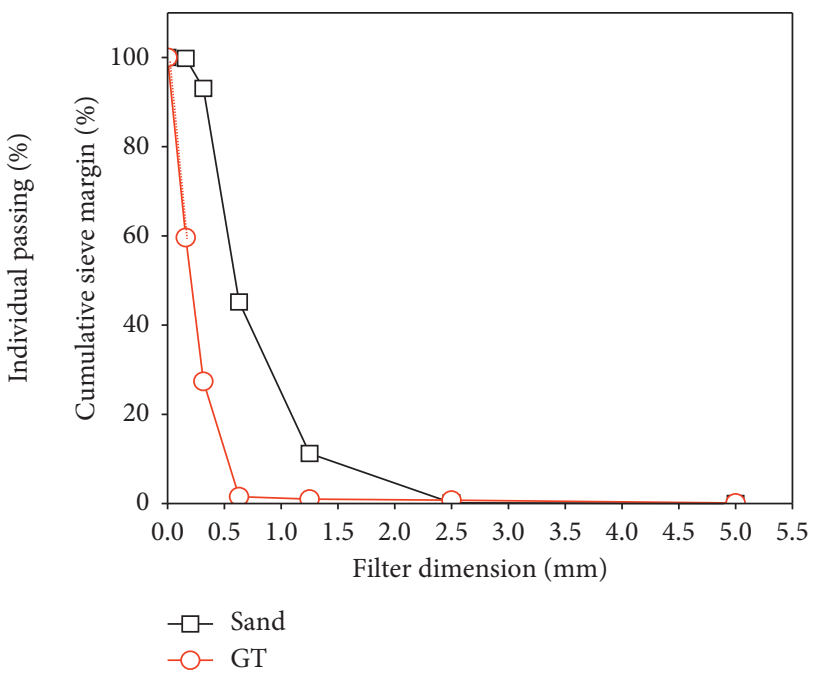

(b)

FIGURE 3: Particle size distribution and granular gradation of GT and sand: (a) particle size distribution; (b) granular gradation.

Table 1: Mechanical properties of Portland cement (MPa).

\begin{tabular}{lcccccc}
\hline \multirow{2}{*}{ Flexural strength $(\mathrm{MPa})$} & \multicolumn{2}{c}{ Compressive strength } & Fineness & \multicolumn{2}{c}{ Setting time (min) } \\
\hline 3 days & 28 days & 3 days & 28 days & 1.2 & Initial setting \\
4.1 & 9.3 & 21.2 & 46.1 & & 164 & Final setting \\
\hline
\end{tabular}

TABle 2: Chemical properties of Portland cement, sand, and graphite tailings (\%).

\begin{tabular}{|c|c|c|c|c|c|c|c|c|c|}
\hline Materials & & & & $\mathrm{Ch}$ & compo & & & & \\
\hline Cement & $\begin{array}{c}\mathrm{CaO} \\
59.64 \\
\end{array}$ & $\begin{array}{c}\mathrm{SiO}_{2} \\
21.47 \\
\end{array}$ & $\begin{array}{c}\mathrm{Al}_{2} \mathrm{O}_{3} \\
5.80 \\
\end{array}$ & $\begin{array}{c}\mathrm{Fe}_{2} \mathrm{O}_{3} \\
4.04 \\
\end{array}$ & $\begin{array}{c}\mathrm{MgO} \\
3.24 \\
\end{array}$ & $\begin{array}{l}\mathrm{SO}_{3} \\
2.08 \\
\end{array}$ & $\begin{array}{l}\text { Loss } \\
2.44 \\
\end{array}$ & & \\
\hline GT & $\begin{array}{c}\mathrm{CaO} \\
15.55 \\
\end{array}$ & $\begin{array}{l}\mathrm{SiO}_{2} \\
62.50 \\
\end{array}$ & $\begin{array}{c}\mathrm{Al}_{2} \mathrm{O}_{3} \\
10.21\end{array}$ & $\begin{array}{c}\mathrm{Fe}_{2} \mathrm{O}_{3} \\
5.07\end{array}$ & $\begin{array}{c}\mathrm{MgO} \\
2.33 \\
\end{array}$ & $\begin{array}{l}\mathrm{SO}_{3} \\
0.54 \\
\end{array}$ & $\begin{array}{c}\mathrm{V}_{2} \mathrm{O}_{5} \\
0.42\end{array}$ & $\begin{array}{l}\mathrm{K}_{2} \mathrm{O} \\
2.26\end{array}$ & $\begin{array}{l}\text { Loss } \\
1.17 \\
\end{array}$ \\
\hline Sand & $\begin{array}{c}\mathrm{SiO}_{2} \\
99.80\end{array}$ & $\begin{array}{l}\text { Loss } \\
0.02\end{array}$ & & & & & & & \\
\hline
\end{tabular}

TABLE 3: Mineral content of cement and graphite tailings (\%).

\begin{tabular}{lccccccc}
\hline \multirow{2}{*}{ Cement } & $\mathrm{C}_{3} \mathrm{~S}$ & $\mathrm{C}_{2} \mathrm{~S}$ & $\mathrm{C}_{4} \mathrm{AF}$ & $\mathrm{C}_{3} \mathrm{~A}$ & Gypsum & Semiwater gypsum & Impurities \\
& 65.70 & 18.10 & 8.50 & 4.70 & 2.10 & 0.20 & 0.07 \\
\hline \multirow{2}{*}{ Graphite tailings } & Hematite & Clay & Plagioclase & Quartz & Black mica & Impurities & LOI \\
& 1.1 & 7.4 & 41.4 & 38.3 & 8.6 & 4.15 \\
\hline
\end{tabular}

TABLE 4: Properties of sand and graphite tailings.

\begin{tabular}{lcc}
\hline Type & Natural stand & Graphite tailings \\
\hline Size $(\mathrm{mm})$ & $0.16-5$ & $0.2-0.4$ \\
Apparent density $\left(\mathrm{kg} / \mathrm{m}^{3}\right)$ & 2,620 & 2,855 \\
Bulk density $\left(\mathrm{kg} / \mathrm{m}^{3}\right)$ & 1,630 & 1,540 \\
24-hour water absorption $(\%)$ & 21.8 & 36.7 \\
Fineness modulus & 2.49 & 0.90 \\
pH value & 7.0 & 10.0 \\
\hline
\end{tabular}


TABLE 5: Mixing proportions of GTCM $\left(\mathrm{kg} / \mathrm{m}^{3}\right)$.

\begin{tabular}{lccccc}
\hline W/C $=0.4$ & Cement & Water & Sand & Graphite tailings & Superplasticizer (\%) \\
\hline GTCM-0 & 689.70 & 275.90 & 1034.50 & 0 & 0.05 \\
GTCM-10 & 689.70 & 275.90 & 931.05 & 103.50 & 0.05 \\
GTCM-20 & 689.70 & 275.90 & 827.60 & 206.90 & 0.06 \\
GTCM-30 & 689.70 & 275.90 & 724.15 & 310.35 & 0.11 \\
GTCM-40 & 689.70 & 275.90 & 620.70 & 413.80 & 0.26 \\
\hline
\end{tabular}

TABLE 6: Curing schemes of GTCM.

\begin{tabular}{lccccc}
\hline Curing schemes & Curing method abbreviation & Curing days & Curing temperature & Relative humidity (RH) & Note \\
\hline $\begin{array}{l}\text { Standard curing } \\
\text { Hot-water curing }\end{array}$ & SC [33] & $1 \mathrm{~d}, 3 \mathrm{~d}$ & $20^{\circ} \mathrm{C}$ & $95 \%$ & Curing $1 \mathrm{~d}$ and $3 \mathrm{~d}$ \\
& HWC [34] & $1 \mathrm{~d}, 3 \mathrm{~d}$ & $60^{\circ} \mathrm{C}$ & $100 \%$ (in water) & Curing $1 \mathrm{~d}$ and $3 \mathrm{~d}$ \\
Combined curing & CC [35] & $1 \mathrm{~d}, 3 \mathrm{~d}$ & $20^{\circ} \mathrm{C}+60^{\circ} \mathrm{C}$ & $100 \%$ (in water) & $\begin{array}{r}3 \mathrm{~d}: 20^{\circ} \mathrm{C}-12 \mathrm{~h}+60^{\circ} \mathrm{C}-12 \mathrm{~h} \\
\end{array}$ \\
& & & & $3 \mathrm{~d}: 20^{\circ} \mathrm{C}-2 \mathrm{~d}-2 \mathrm{~d}+60^{\circ} \mathrm{C}-1 \mathrm{~d}$ \\
\hline
\end{tabular}

different curing methods. The preparation and drying conditions of these samples were in accordance with Chinese regulations GB/T 21650-2008 [37], GB/T 16594-2008 [38], GB/T 30904-2014 [39], and ISO 19618-2017 [40].

\section{Results and Discussion}

3.1. Mechanical Properties of the GTCM. The flexural strength is the most critical material property of cement mortar and determines its engineering application and development prospects. In this paper, experimental results of the flexural strength of the GTCM specimens with different curing methods are shown in Figure 4. (1) After curing for 1 day, the order of influence of three curing methods on the development of the GTCM flexural strength is HWC $>$ SC $>$ CC, and the flexural strength of the cement mortar is well developed with the HWC method. Although the HWC method is also present in the CC method, the flexural strength cannot be sufficiently developed due to the insufficient curing time in hot water. Therefore, the HWC method is most beneficial for quickly improving the 1-day flexural properties of cement mortar. Simultaneously, GT has a significant influence on the flexural strength with each curing method. With an increasing amount of GT, the flexural strength obviously increases and then slightly decreases with the HWC method, but the flexural strength has a nonlinear trend with the SC and CC methods, especially when the GT content is $40 \%$ in the CC method, where the flexural strength is the lowest.

When the amount of graphite tailings is appropriate, the cement mortar is denser. That is, the distance between aggregates and the distance between aggregates and cement particles are smaller. With curing time increasing, the unhydrated particles are decreasing, and then hydration production is increasing in the whole hydration reaction. If the cement mortar is always cured by SC or HWC, the rate of decreasing unhydrated particles and increasing hydration production is similarly increasing. However, hot-water conditions have a great advantage in stimulating GT activity and improving the performance of the cement mortar after 1 day. However, when the graphite tailing content is $40 \%$, the particles in cement mortar are so dense that the space of increased hydration production is slightly more than the space of decreased unhydrated particles. During the standard curing process of the front part of the combined curing, $\mathrm{C}-\mathrm{S}-\mathrm{H}$ is generated, which is located between unhydrated particles and water required for the hydration reaction, which slightly hinders the diffusion of cement particles such as tricalcium silicate in solution [41]. During the hot-water curing process in the later stage, the growth rate of C-S-H is greater than the reduction rate of unhydrated particles. This phenomenon causes weak internal stress in the mortar, resulting in a reduction in flexural strength which is more sensitive to this phenomenon than compressive strength. After one day of combined curing, the reduction of flexural strength does not exceed $0.4 \mathrm{MPa}$. When the combined curing is performed for three days, the standard curing time is longer, increasing the time for cement particles to dissolve and react, leaving space for the generation of hydration products. When hot-water curing begins, hydration products are accelerated to fill the pores between the particles, and the strength is improved.

The combined effect of the HWC method and a GT content of $20 \%$ shows the best improvement for the synergistic development of the flexural strength of the GTCM after 1 day, and the maximum value is 7.6 MPa. (2) The 3-day flexural strength is significantly affected by the combined influence of the GT and curing methods. The HWC method also improves the mechanical properties of the GTCM, especially in combination with the incorporation of GT. For the GT incorporation of $10 \%$ to $40 \%$, the combination of the HWC method and GT improves the flexural strength of the GTCM. When the GT incorporation is $20 \%$ and the HWC method is used, the flexural strength of the GTCM reaches a maximum value of $10.8 \mathrm{MPa}$. In addition, when the GT incorporation is $20 \%$ and $30 \%$ and the CC: $2-1$ method is used, the flexural strength can be improved, although the improvement is smaller compared with the HWC method. However, the combination of the SC method and GT incorporation results in a very small 


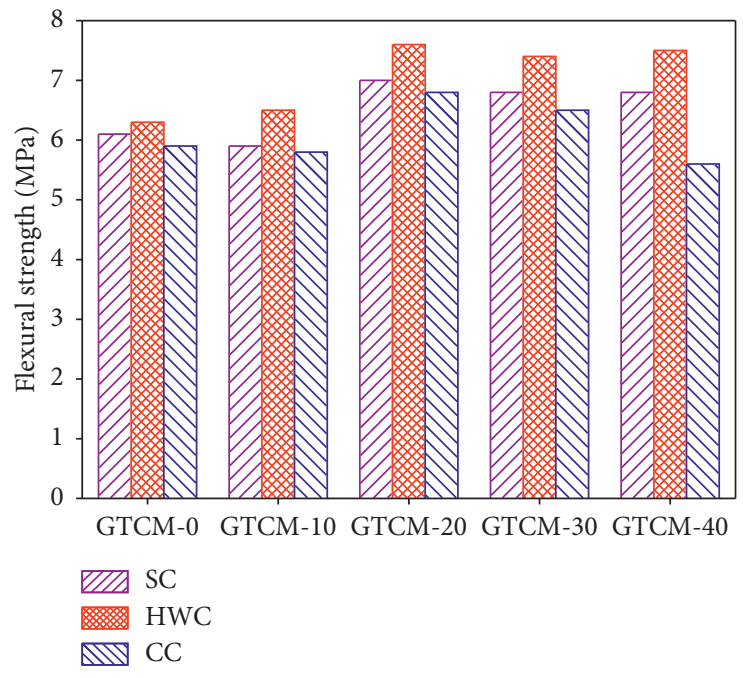

(a)

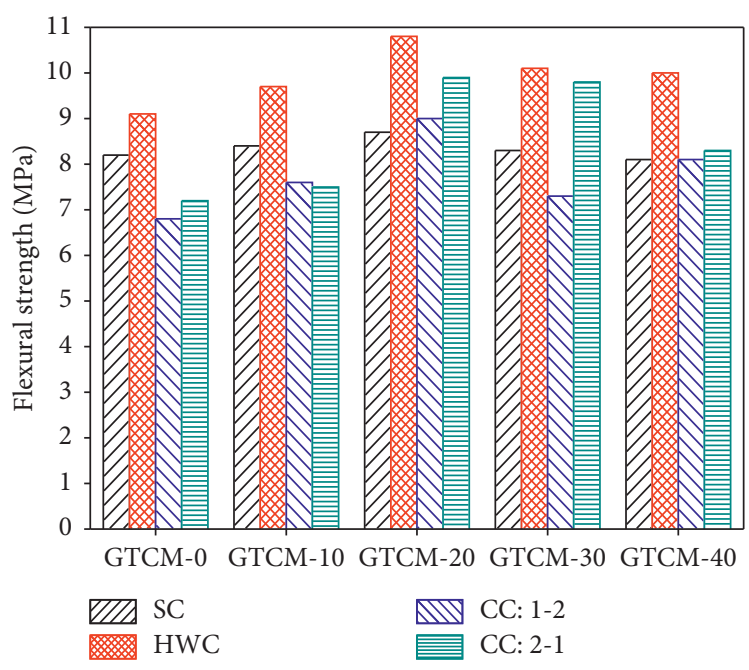

(c)

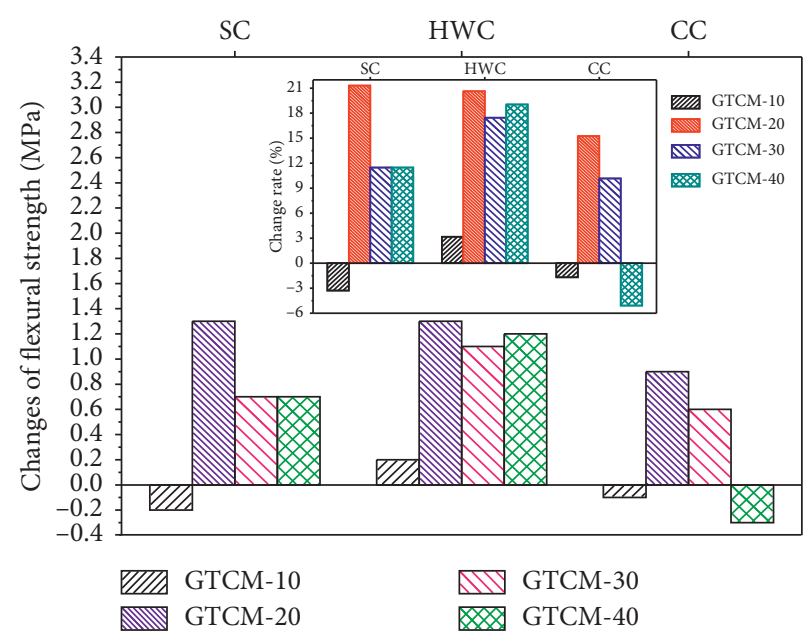

(b)

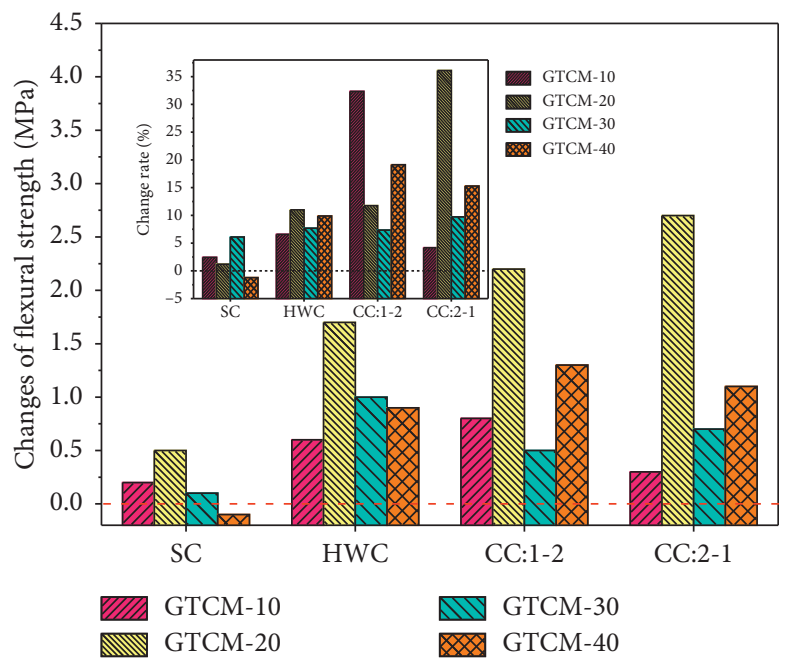

(d)

FIgURE 4: Flexural strength of GTCM under different cure methods: (a) 1 day; (b) changes of 1 day; (c) 3 days; (d) changes of 3 days.

change in the flexural strength, and the flexural strength for $30 \%$ and $40 \%$ GT incorporation is inferior to that of the pure cement mortar.

Another major mechanical indicator for cement mortar is the compressive strength. The compressive strength of the GTCM is shown in Figure 5. The results show that the HWC and CC methods have a significant effect on the development of compressive strength. However, the SC method has an inhibitory effect on the development of the compressive strength of the GTCM, especially when the GT incorporation is greater than $20 \%$ at 3 days. The maximum compressive strength of the GTCM is for a combination of $20 \%$ GT and the HWC method, and the values are $39.8 \mathrm{MPa}$ for 1 day and $51.3 \mathrm{MPa}$ for 3 days. In summary, the GT and HWC methods have an important impact on the mechanical properties of GTCM. For emergency engineering, repair, and reinforcement projects, construction of critical structures or high-performance building materials, the incorporation of $20 \%$ GT and the use of the HWC method, is the best way to improve the mechanical properties of the materials and facilitate an effective and convenient structural construction. The comprehensive mechanisms of the GT and curing methods on the early performance of GTCM are further explored through mesostructure changes (Section 3.2) and quantitative and graphical models (Section 3.3).

3.2. Material Characterization of the GTCM. The GTCM specimens under the combined effect of $0 \%$ and $20 \%$ GT and the HWC method were selected for analysis of the 1-day and 3 -day macroscopic performance changes. The SC method is commonly used in engineering, and the results of the mesocharacteristics as a result of this method were used for comparative analysis.

3.2.1. Material Morphology of the GTCM. Changes in the material morphology of GTCM-0 and GTCM-20 during the SC and HWC methods are determined based on SEM and 


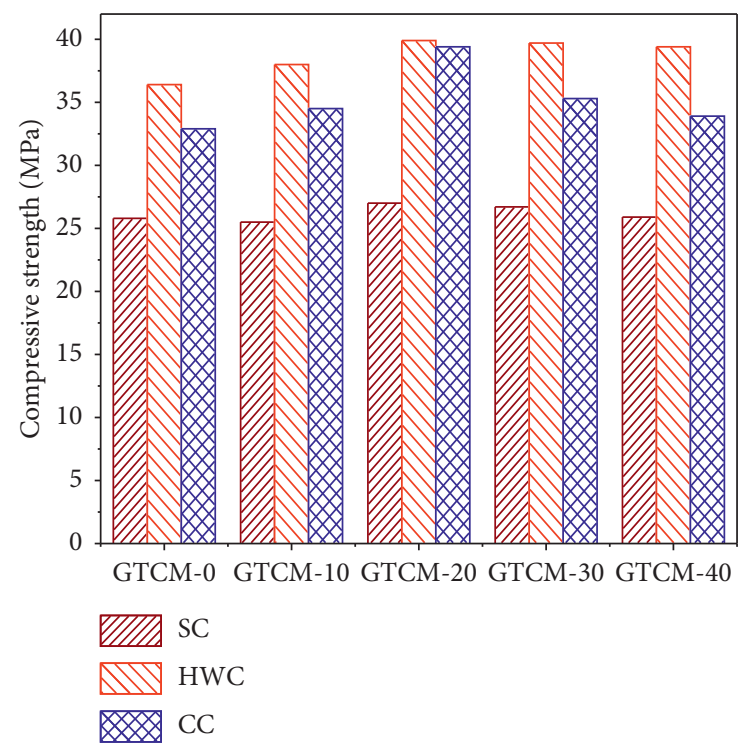

(a)

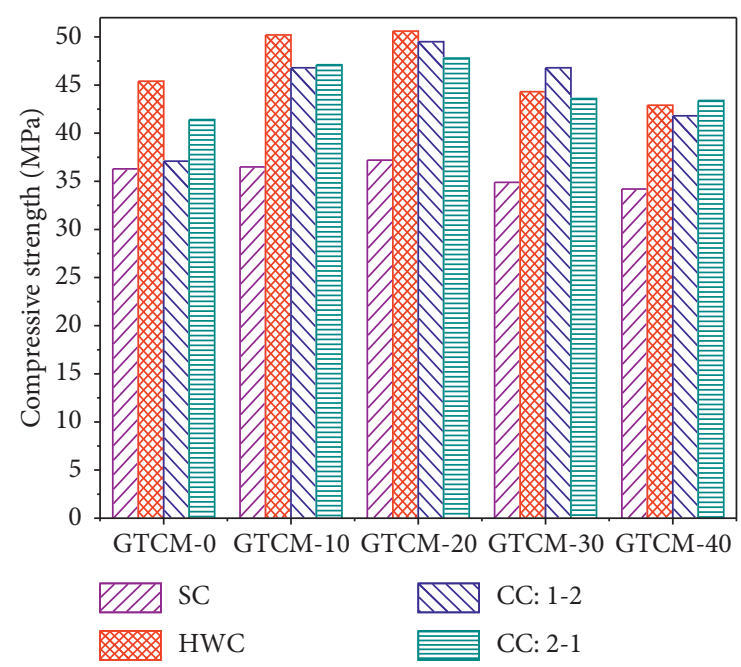

(c)

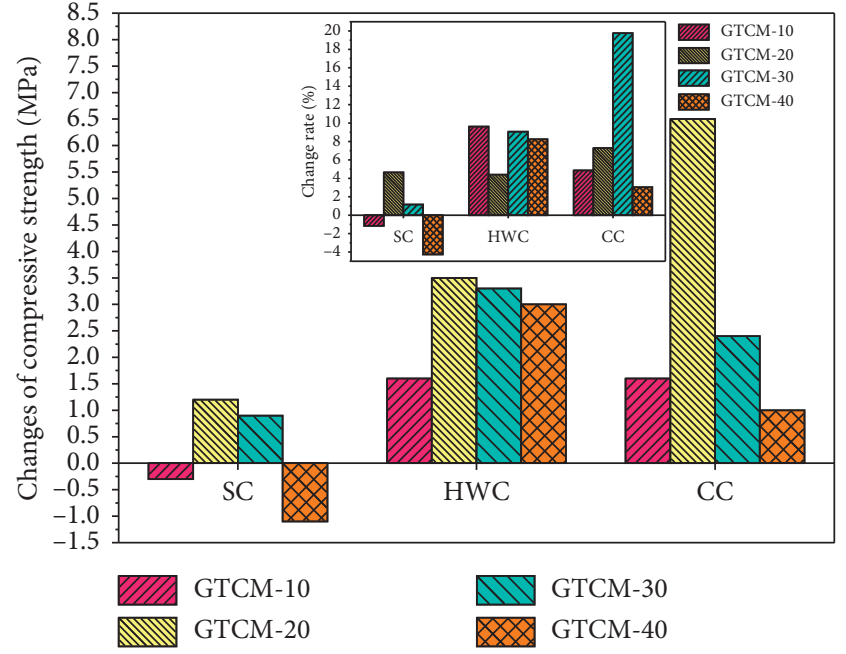

(b)

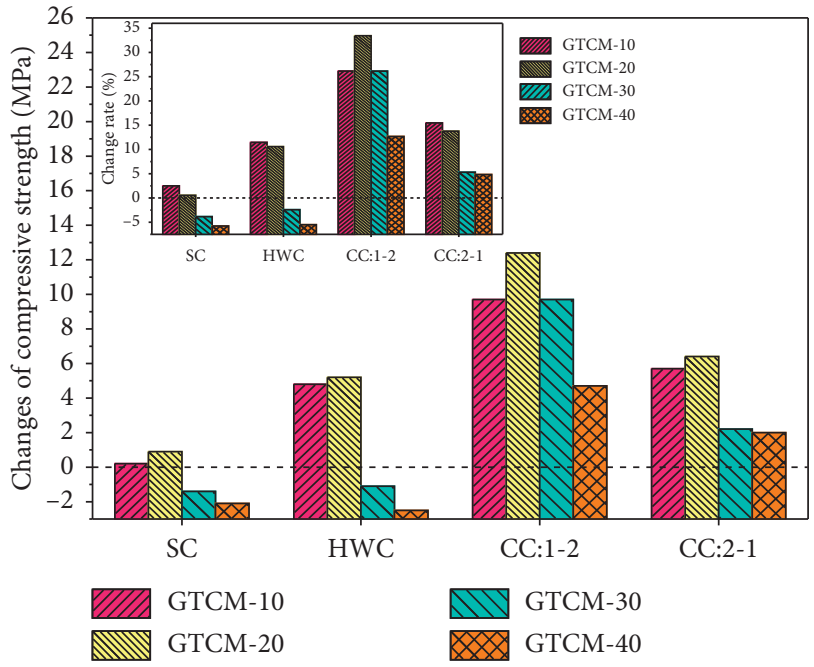

(d)

Figure 5: Compressive strength of GTCM under different cure methods: (a) 1 day; (b) changes of 1 day; (c) 3 days; (d) changes of 3 days.

are shown in Figures 6 and 7. There was a substantial amount of flocculating hydration products in GTCM-0 and a substantial amount of cement particles that were not involved in the hydration reaction in GTCM-20 under the SC method after 1 day. Due to insufficient hydration, cementation strength was low, and many internal defects were present in GTCM-0. At this point, the presence of the GT in GTCM-20 did not change the poor hydration state simply because the low fineness changed the internal defect density, resulting in an increase in the macroscopic strength compared with GTCM-0. The hot-water condition partially improved the unhydrated state in GTCM-0, the flocculating hydration product decreased, and the solid hydration product increased. At the same time, the unhydrated cement particles in GTCM-20 almost disappeared, and a relatively complete solid and filamentous hydration product was formed. The combination of GT and hot water made the cement mortar curing more complete after 1 day. After curing for 3 days, there was still a certain amount of flocculating hydration products and cement clinker in GTCM-0 and GTCM-20 under the SC method, but hot-water conditions can change the aforementioned disadvantages, and with the incorporation of the GT, the cement inside the cement mortar was denser. Therefore, the combination of GT and HWC can improve the shortcomings of insufficient hydration and weak cementation of cement mortar to some extent and reduce internal defects, which provides better early mechanical properties.

3.2.2. Hydration Products in the GTCM. The early hydration products of GTCM-0 and GTCM-20 under the SC and HWC methods are shown in Figures 8 and 9, respectively. For GTCM-0, the peak value and area of $\mathrm{CH}$ increase with 


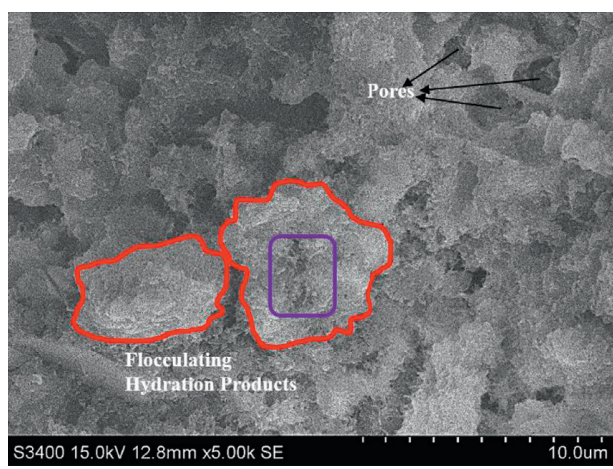

(a)

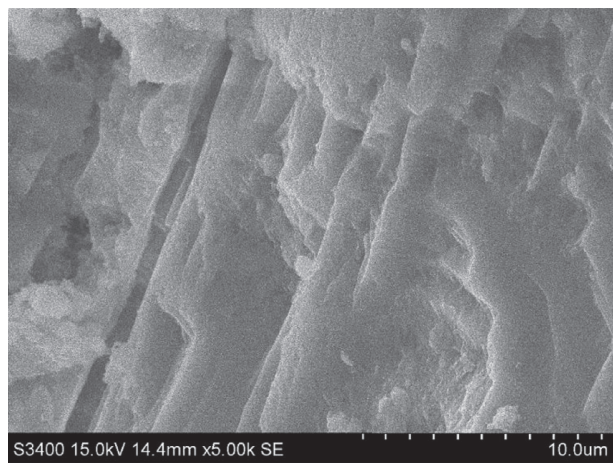

(c)

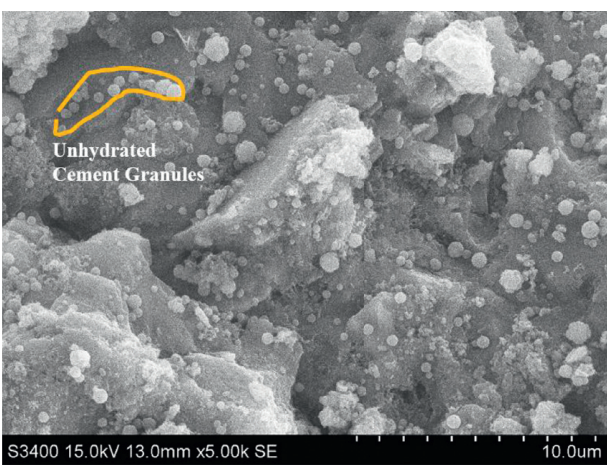

(b)

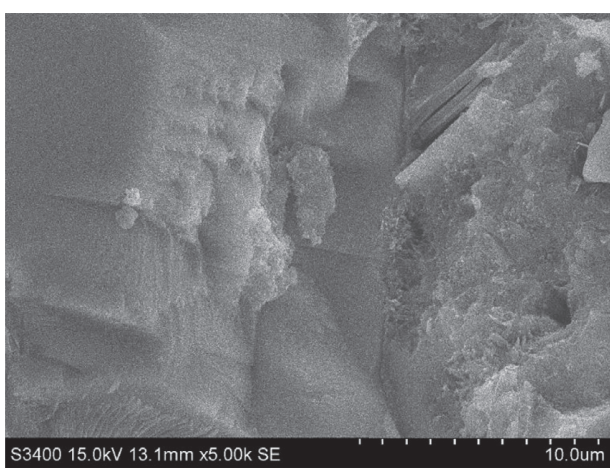

(d)

Figure 6: Mesomorphology of GTCM for 1 day: (a) GTCM-0 under the SC method; (b) GTCM-20 under the SC method; (c) GTCM-0 under the HWC method; (d) GTCM-20 under the HWC method.

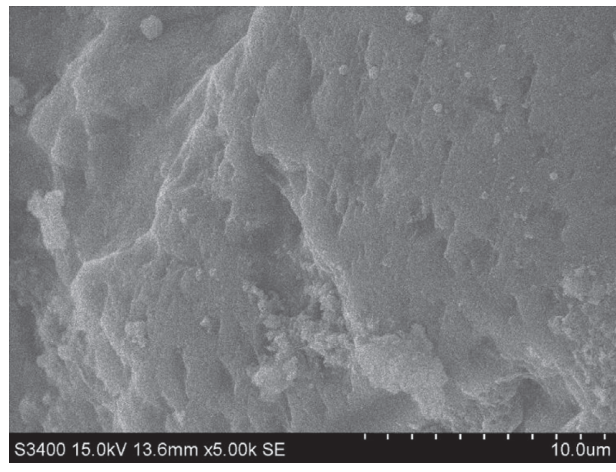

(a)

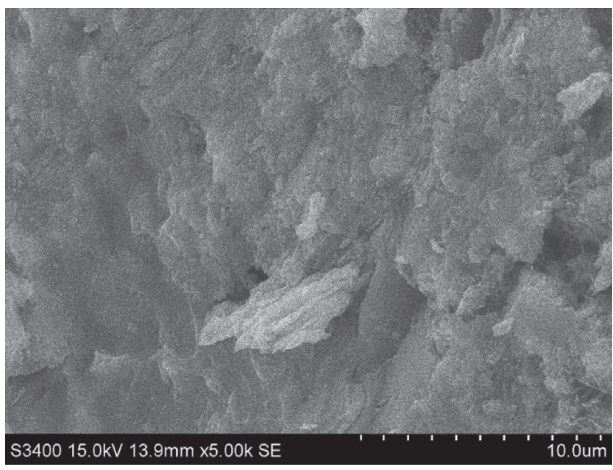

(c)

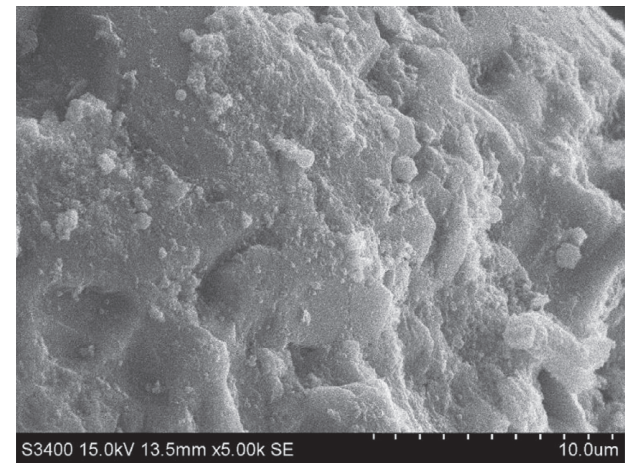

(b)

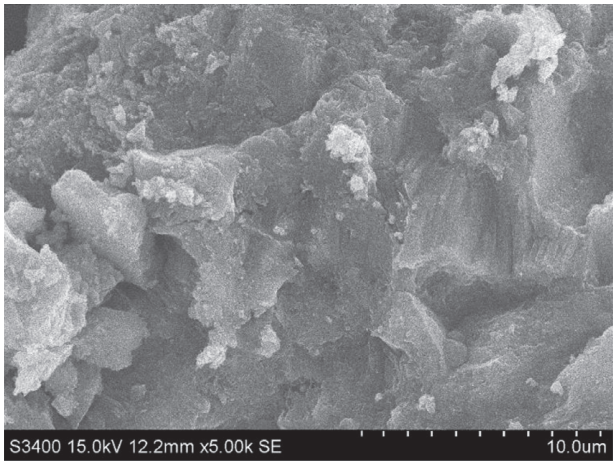

(d)

Figure 7: Mesomorphology of GTCM for 3 days: (a) GTCM-0 under the SC method; (b) GTCM-20 under the SC method; (c) GTCM-0 under the HWC method; (d) GTCM-20 under the HWC method. 


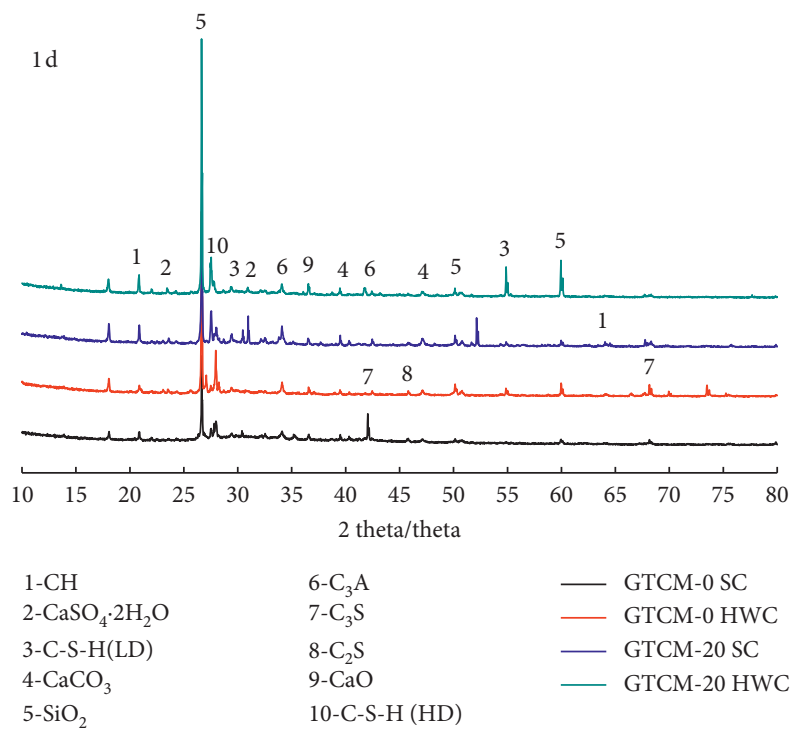

(a)
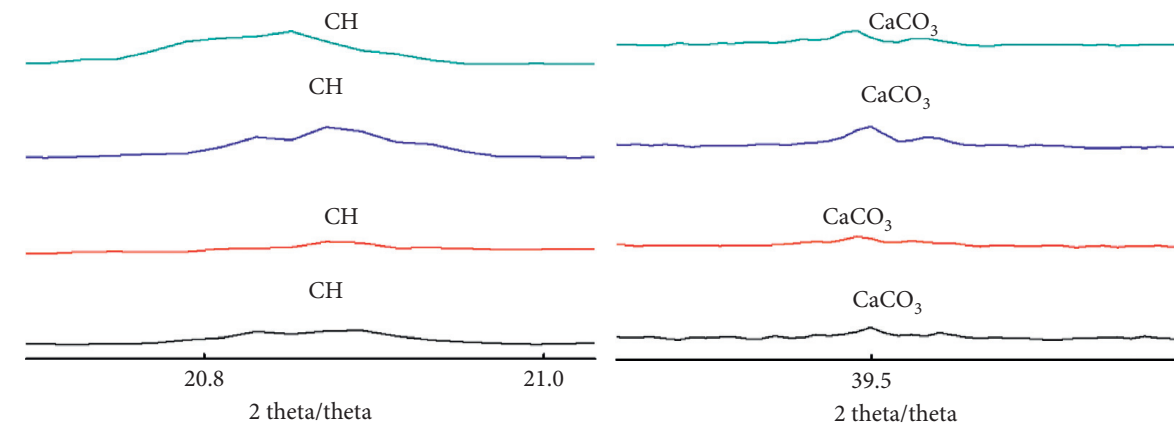

$\mathrm{H}$

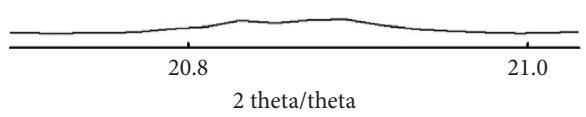

2 theta/theta
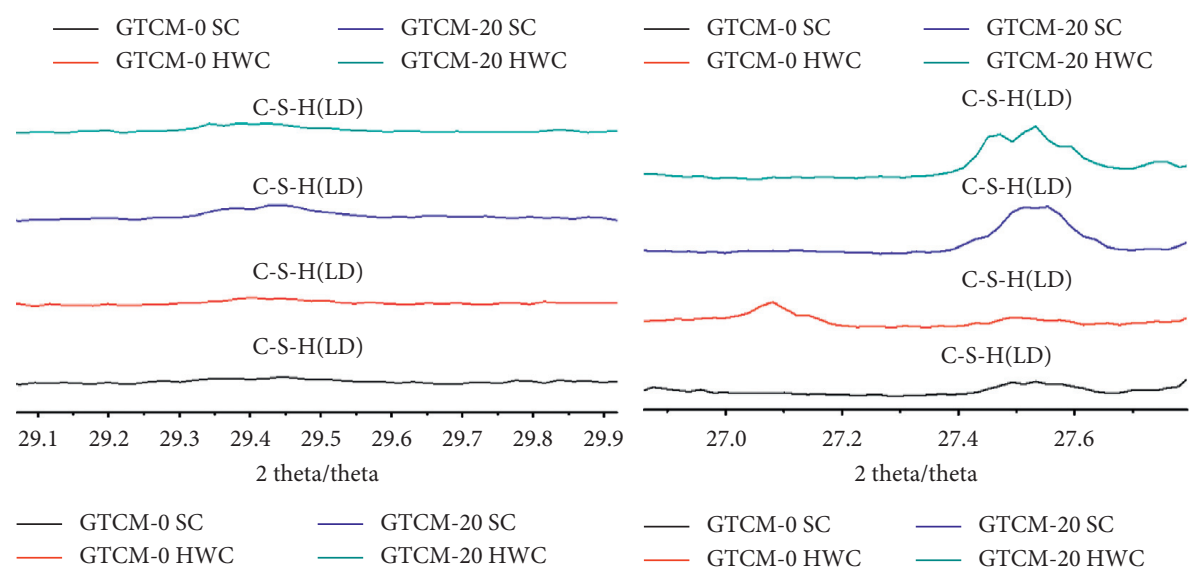

(b)

FIgURE 8: Hydration product analysis of GTCM-0 and GTCM-20 under SC and HWC methods for 1 day.

curing times from 1 day to 3 days, but the peak value an area of $\mathrm{CH}$ under the $\mathrm{HWC}$ method after 3 days are less than those of the SC method due to the accelerated precipitation as a result of the hot-water conditions. The content of the hydrated calcium carbonate product does not change significantly, and AFt appears only under 1 day of hot-water curing. When the curing time increases from 1 day to 3 days, the content of $\mathrm{C}-\mathrm{S}-\mathrm{H}(\mathrm{LD}, \mathrm{Ca} / \mathrm{Si}<1.5)$ increases, but the content of $\mathrm{C}-\mathrm{S}-\mathrm{H}(\mathrm{HD}, \mathrm{Ca} / \mathrm{Si}>1.5)$ decreases. The hot-water curing conditions significantly increase the peak areas of C-S-H (LD) and C-S-H (HD). The change in the hydration product for GTCM-20 is different than that for GTCM-0. The peak value and area of $\mathrm{CH}$ in GTCM-20 increase as the curing time increases from 1 day to 3 days, and there is no significant decrease in the hot-water condition because $\mathrm{CaO}$ contained in the GT promotes the formation of $\mathrm{CH}$ to counteract the rapid precipitation of $\mathrm{CH}$. The peak value of $\mathrm{CaCO}_{3}$ is lower after the 1-day hot-water cure than that after the standard cure but higher than that of SC after 3 days. The 


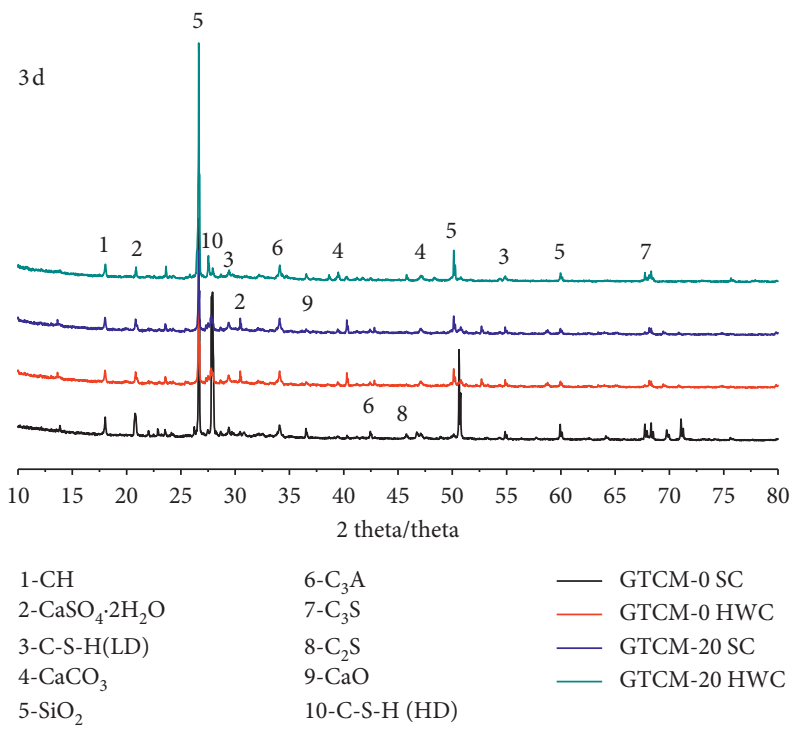

(a)
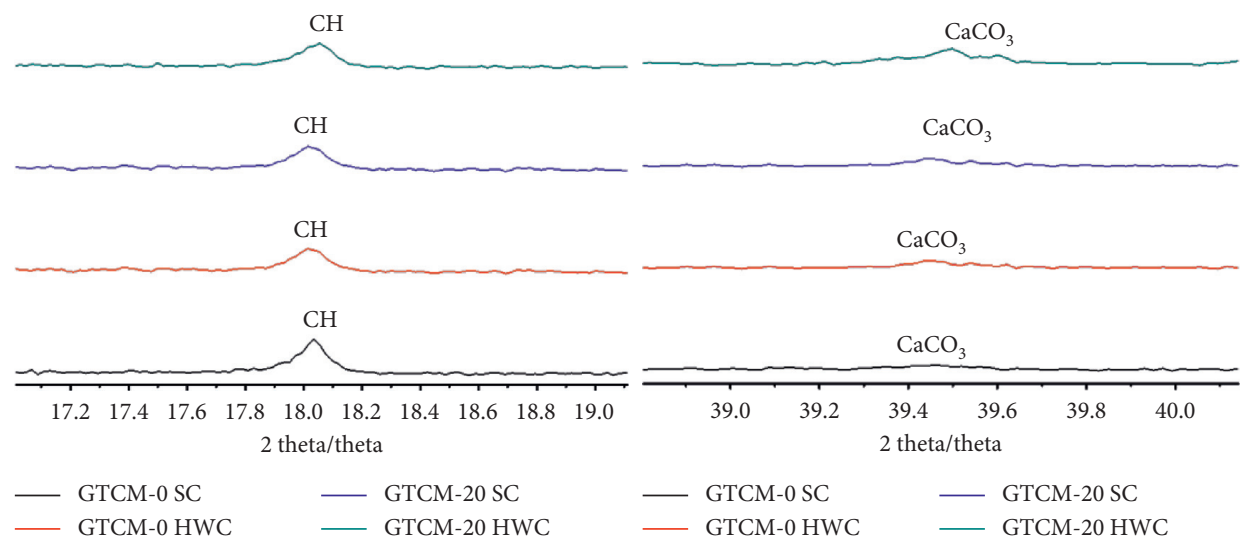

GTCM-0 HWC

- GTCM-20 HWC

- GTCM-0 SC - GTCM-20 SC
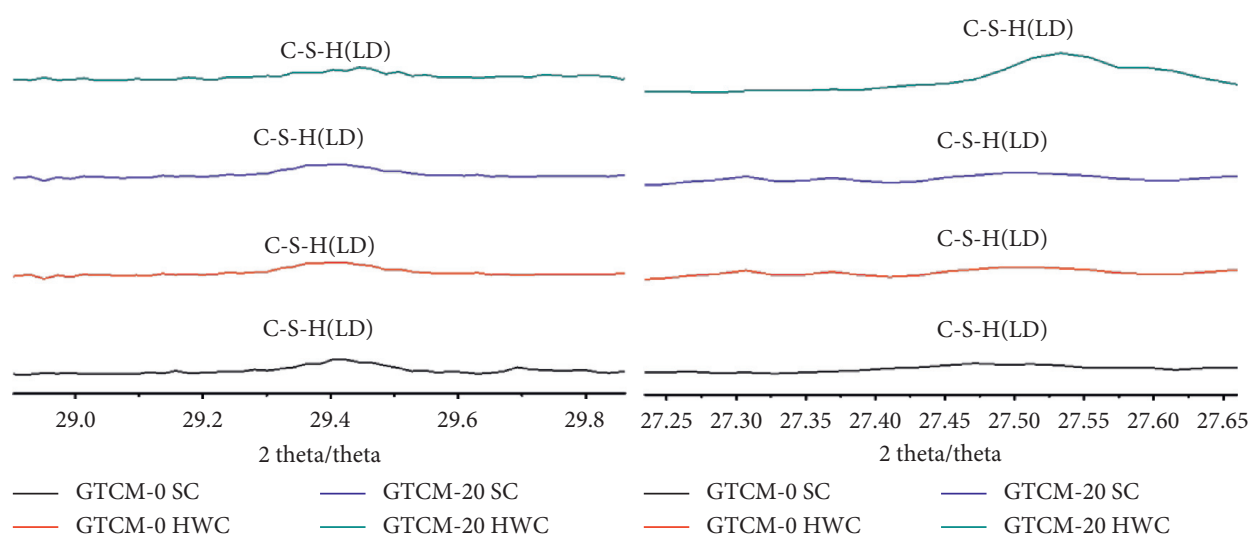

(b)

FIGURE 9: Hydration product analysis of GTCM-0 and GTCM-20 under SC and HWC methods for 3 days.

significant change in GTCM-20 is the amount of C-S-H gel produced. The GT leads to the generation of more C-S-H (HD), but AFt generation does not improve. The combination of the GT and the HWC method results in a large amount of C-S-H formation in the cement mortar after 3 -day curing, which greatly solidifies the matrix and results in improved mechanical properties.
3.2.3. Functional Group Changes in the GTCM. In this paper, the effects of the GT and curing methods on the early performance of GTCM were also analyzed by the changes in the functional groups. The changes in the functional groups of the GTCM are determined based on FTIR and are shown in Figure 10. After 1-day curing, the contraction vibration of the - $\mathrm{OH}$ functional group (3644) in $\mathrm{CH}$ is more apparent in 

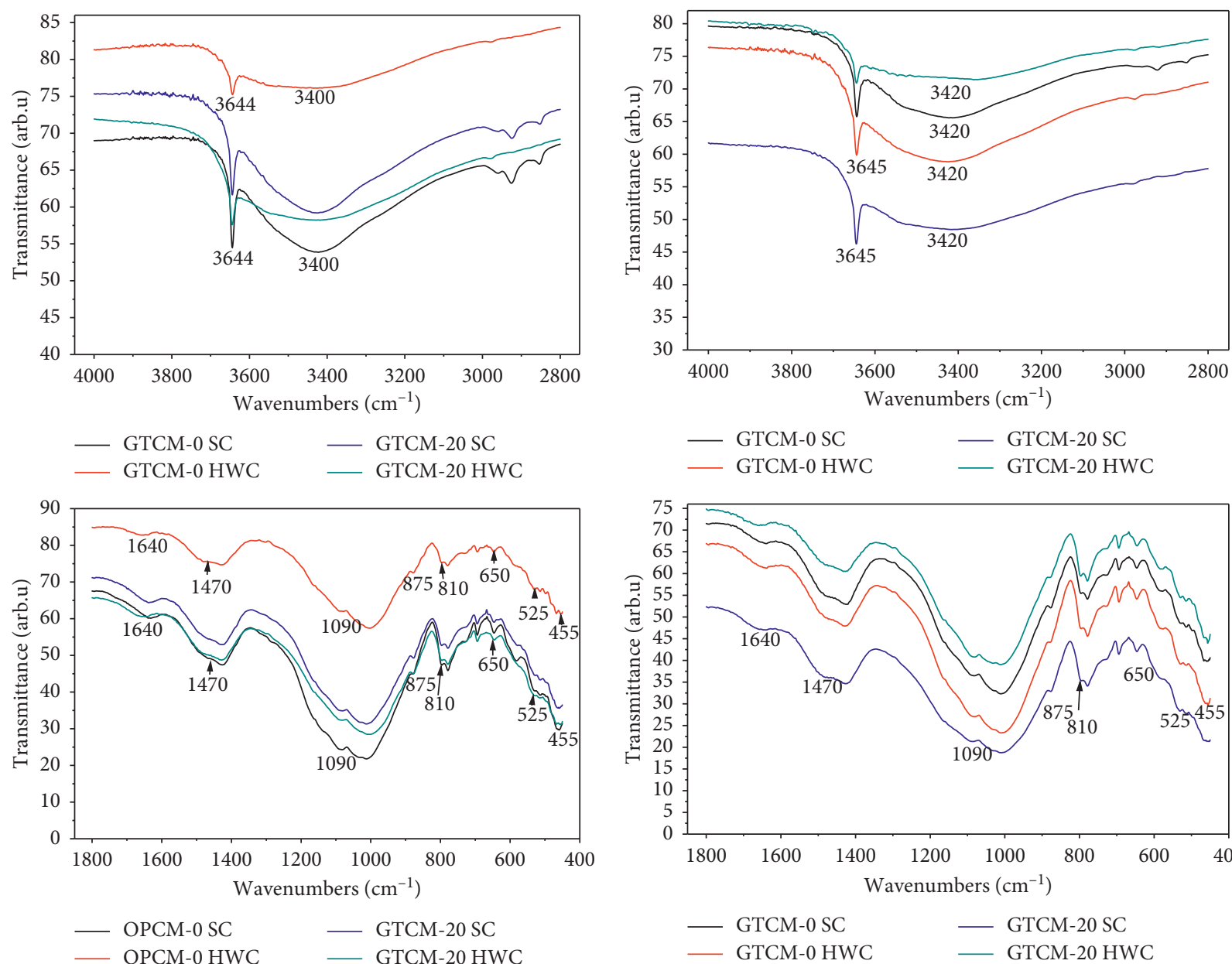

(a)

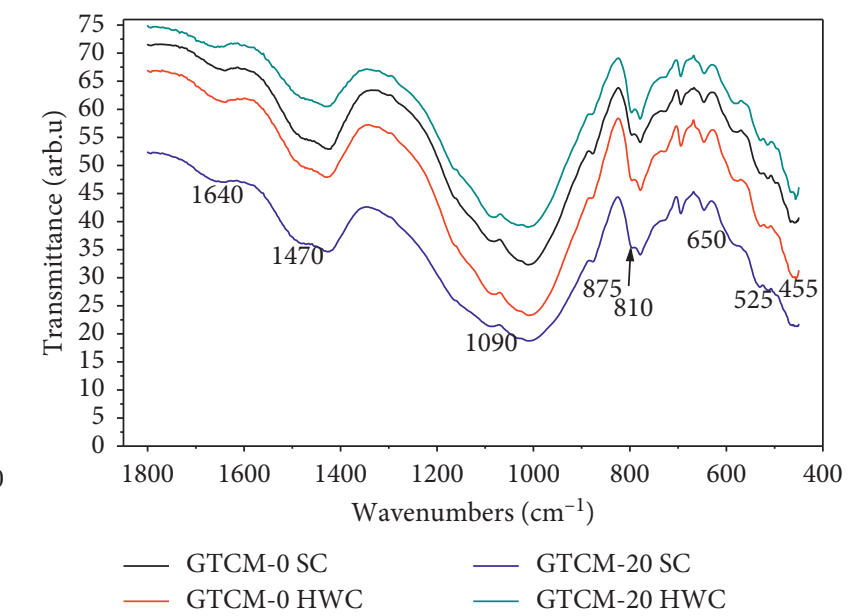

(b)

FIgUre 10: Functional group analysis on GTCM-0 and GTCM-20 under SC and HWC methods: (a) 1 day and (b) 3 days.

the SC method than in the HWC method, and the shrinkage vibration of the $\mathrm{H}-\mathrm{O}-\mathrm{H}$ (3400) functional group is not obvious in the HWC method. The bending vibration of $\mathrm{H}-\mathrm{O}-\mathrm{H}(\mathbf{1 6 4 0})$ is not significantly affected by changes in curing methods. The acceleration of water evaporation in the matrix due to hot water or the dehydration of $\mathrm{CH}$ is caused only by the change in the contraction vibration of -O-H. The GT incorporation promoted the contraction vibration of the $-\mathrm{OH}$ functional group in $\mathrm{CH}$ and offsets the effect of hot water on its vibration but does not offset the effect of hot water on the $-\mathrm{O}-\mathrm{H}$ functional group in the aqueous phase and even reduces its vibration. Simultaneously, GT also reduces the intensity of the $\mathrm{Si}-\mathrm{O}$ stretching vibration absorption peak in the Q3 tetrahedron (650). However, the width of the Si-O-Si bending vibration band increases so that the $\mathrm{Si}-\mathrm{O}-\mathrm{Si}$ bond angle and the polymer increase, and $\mathrm{Ca} / \mathrm{Si}$ of the hydration product reaches 1.19 (the vibration intensity is lowered to indicate that $\mathrm{Ca} / \mathrm{Si} \geq 1.19)$ rapidly. When the curing time is 3 days, the incorporation of the GT improves the contraction vibration of the $-\mathrm{OH}$ functional group in $\mathrm{CH}$, and the HWC method does not reduce the vibration of $\mathrm{CH}$ or the bending vibration of $\mathrm{H}-\mathrm{O}-\mathrm{H}$ in GTCM- 0 but significantly reduces them in GTCM-20. The Si-O out-ofplane bending vibration absorption peak (525) and the Si-O in-plane bending vibration absorption peak (455) vary significantly under the combined effect of the GT and HWC method; that is, the degree of polymerization of the cementitious material gradually increases with the hydration process to form a C-S-H gel with an increased density.

3.2.4. Analysis of the Pore Structure Distribution in the GTCM. The pore structure distribution, porosity, total pore volume, pore area, and pore percentage in the GTCM during different curing methods after 1 day and 3 days are shown in Figure 11 and Table 7. The cumulative pore volume percentage is shown in Figure 12. The cumulative pore volume percentages are divided according to the principle of harmless pores $(<20 \mathrm{~nm})$, less harmful pores $(20-100 \mathrm{~nm})$, harmful pores $(100-1000 \mathrm{~nm})$, and very harmful pores $(>1000 \mathrm{~nm})$. The results show the following. (1) After 1 day, the main peak in the pore size distribution of GTCM- 0 and GTCM-20 moved from $62.5 \mathrm{~nm}$ to $26.2 \mathrm{~nm}$, respectively; it changes from $62.1 \mathrm{~nm}$ to $21.2 \mathrm{~nm}$ for the SC to HWC 


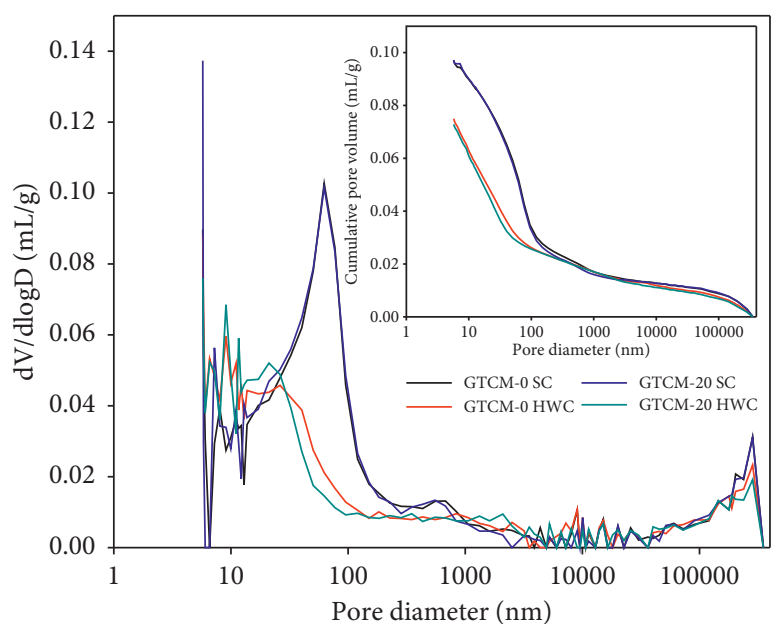

$\begin{array}{ll}\text { GTCM-0 SC } & \text { GTCM-20 SC } \\ \text { GTCM-0 HWC } & - \text { GTCM-20 HWC }\end{array}$

(a)
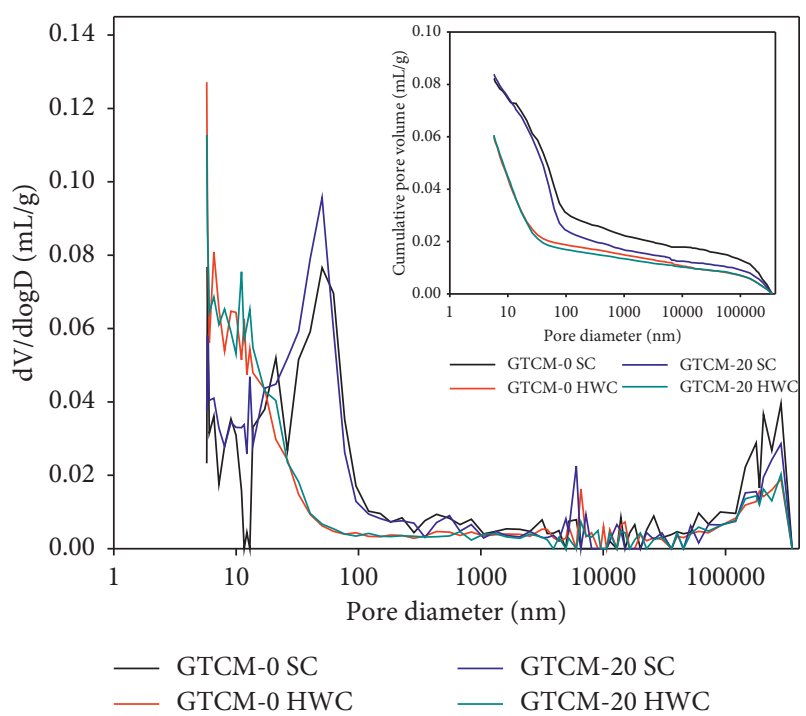

(b)

Figure 11: Pore size distribution of GTCM-0 and GTCM-20 under SC and HWC methods: (a) 1 day and (b) 3 days.

Table 7: Porosity, total pore size, and area of GTCM-0 and GTCM-20 under SC and HWC methods.

\begin{tabular}{cccccc}
\hline Age $(\mathrm{d})$ & Specimen number & Curing scheme & Porosity $(\%)$ & Total intrusion volume $(\mathrm{mL} / \mathrm{g})$ & Total pore $\operatorname{area}\left(\mathrm{m}^{2} / \mathrm{g}\right)$ \\
\hline \multirow{2}{*}{1} & GTCM-0 & SC & 19.1284 & 0.097 & 11.162 \\
& & HWC & 14.9371 & 0.075 & 13.134 \\
& GTCM-20 & SC & 19.0719 & 0.097 & 11.086 \\
& & HWC & 14.7349 & 0.073 & 13.112 \\
\hline \multirow{2}{*}{3} & GTCM-0 & SC & 16.4691 & 0.0839 & 15.068 \\
& & HWC & 12.2389 & 0.0607 & 14.723 \\
& \multirow{2}{*}{ GTCM-20 } & SC & 16.3607 & 0.0723 & 11.794 \\
& & HWC & 12.0793 & 0.0602 & 9.828 \\
\hline
\end{tabular}

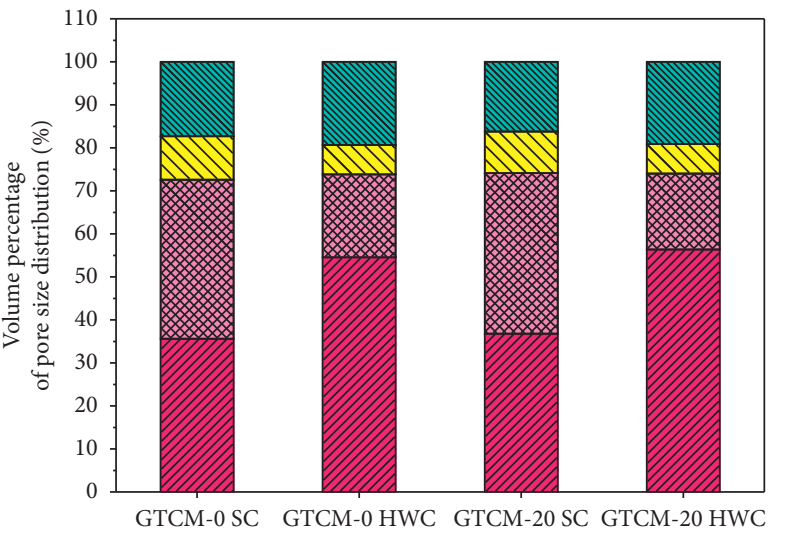

$<20 \mathrm{~nm}$
$20 \sim 100 \mathrm{~nm}$

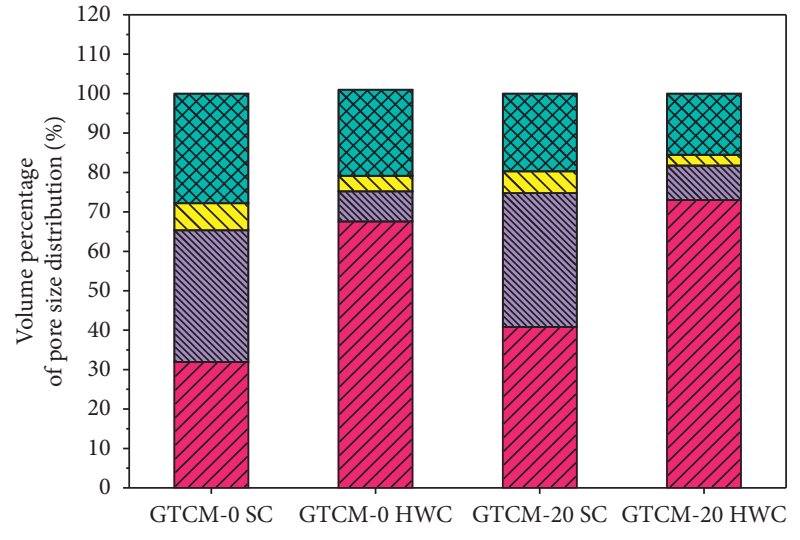

$<20 \mathrm{~nm}$
$20 \sim 100 \mathrm{~nm}$
MIV $100 \sim 1000 \mathrm{~nm}$ $>1000 \mathrm{~nm}$

(a)

(b)

FIgURE 12: Pore volume percentage of GTCM-0 and GTCM-20 under SC and HWC methods: (a) 1 day and (b) 3 days.

methods, respectively; and the peak distribution appears in the range of $10 \mathrm{~nm}$. The HWC method increases the pores in the range of $<20 \mathrm{~nm}$ and $100-1000 \mathrm{~nm}$ but reduces the pore volume within $20 \sim 100 \mathrm{~nm}$ and significantly increases the pore volume $>1000 \mathrm{~nm}$. For GTCM-0, a surge in the amount of AFt after hot-water curing for 1 day results in an increase 

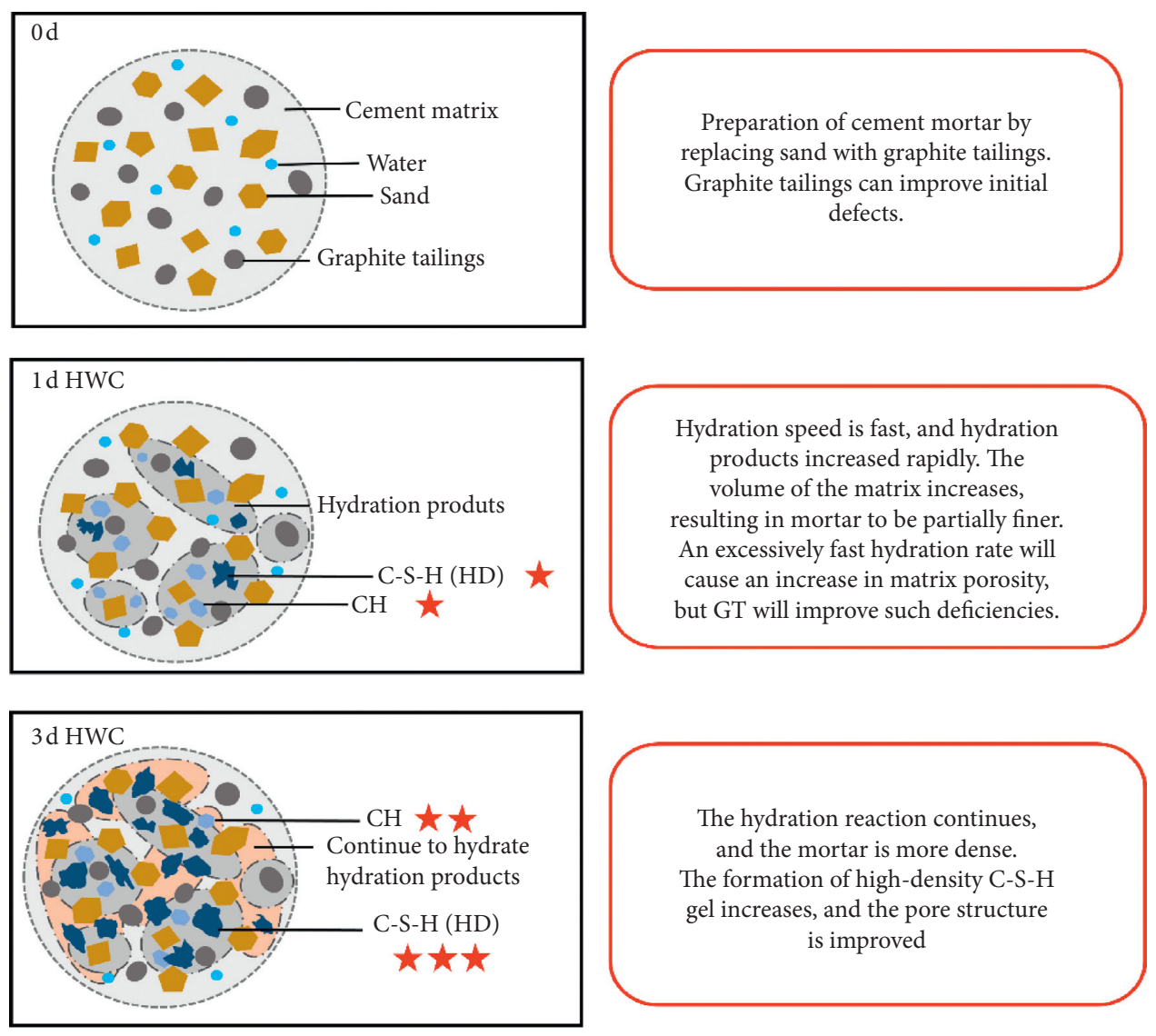

GTCM-20 and HWC

FIGURE 13: Combined effect mechanism diagram of the GT and HWC method on the early structure and performance of cement mortar.

in pores below $20 \mathrm{~nm}$, whereas for CTCM-20, the change is due to the formation of high-density C-S-H. One-day hotwater curing causes the cement-based material to rapidly hydrate, which leads to early cracking, but the early cracking is compensated for due to the volume increase of the $20 \mathrm{~nm}$ pores and the production of C-S-H gel with an increased amount of $\mathrm{Ca} / \mathrm{Si}$ or $\mathrm{AFt}$. The mechanical properties are ultimately improved despite the shortcomings, and the incorporation of GT promotes a reasonable distribution of the pore structure. However, after one day of hot-water curing conditions, this promotion or increase in GT activity is not sufficient due to the short curing time, so there is no substantial change in the pore structure of GTCM-20 as a result of the HWC method. (2) The porosity of GTCM after 3-day curing is less than that of 1-day curing. At this time, the improvement due to the GT on the pore structure is highlighted. On the one hand, due to the increase of $\mathrm{CH}$ and low-density C-S-H gel during the SC method, the main peak position of the pore structure distribution curve of GTCM20 is $50.4 \mathrm{~nm}$ smaller than the main peak position of GTCM$0(50.6 \mathrm{~nm})$. However, under SC conditions, the incorporation of GT also reduces the porosity $(0.2 \%$ loss $)$ and increases the pore size volume fraction with size $<20 \mathrm{~nm}$ and has a significant effect on improving $>1000 \mathrm{~nm}$ pore distribution. Due to the sufficient curing time, hot-water curing conditions are very helpful for the compactness of the materials. For GTCM-0, the hot-water curing conditions increase the volume fraction of pores within $20 \mathrm{~nm}$ and decrease the pore volume ratio beyond $1000 \mathrm{~nm}$ by increasing the content of $\mathrm{CH}$ and $\mathrm{CaCO}_{3}$, while the changes in GTCM-20 are due to the synergistic improvement of the amount of $\mathrm{CH}, \mathrm{CaCO}_{3}$, and high-density C-S-H. Finally, the most reasonable pore structure distribution can be obtained by the combined effect of a GT content of $20 \%$ and the HWC method.

3.3. Mechanism of Combining GTand Curing Methods on the Early Performance. Based on the material characterization results of the GTCM under the comprehensive effect of the GT and HWC method, the mechanism of the combined effects is shown in Figure 13. The particle size of graphite tailings is smaller than that of sand in Figure 3, so graphite tailings and sand can form reasonable particle gradation and reduce the gaps in cement mortar. The activity of graphite tailings is derived from a crystalline compound of calcium oxide and magnesium oxide, but the total composition of the two is only $17.88 \%$ in Table 2 . Larger particles of graphite tailings have a large surface area and act as a support for aggregates. Graphite tailings are less than $60 \mu \mathrm{m}$ particles which only account for $24 \%$ in Figure 3, and there are still few active materials. The overall activity of graphite tailings from small particles is not very high, but after proper hot- 
water curing which promotes hydration, graphite tailings can increase the strength of mortar. Therefore, the mechanism of graphite tailings improving mortar strength is as follows.

$3 \mathrm{CaO} \cdot \mathrm{SiO}_{2}\left(\mathrm{C}_{3} \mathrm{~S}\right)$ and $2 \mathrm{CaO} \cdot \mathrm{SiO}_{2}\left(\mathrm{C}_{2} \mathrm{~S}\right)$ in cement react with water to form C-S-H and $\mathrm{CH}$. The crystalline compound of calcium oxide and magnesium oxide in graphite tailings smaller than $60 \mu \mathrm{m}$ react with water to produce a weakly alkaline compound. Alkali substances further promote the reaction between silicate and calcium ions in the mortar to form C-S-H [41, 42]. However, the promotion of graphite tailings on hydration reaction is limited. Graphite tailings are finer particles. A proper amount $(20 \%-30 \%)$ of graphite tailings and sand can be used as aggregate to form reasonable gradation so that graphite tailings can increase the strength of mortar. If hot-water curing is used, it will not only accelerate the hydration reaction of cement but also accelerate the dissolution and reaction of active substances in graphite tailings, thereby improving the C-S-H gel morphology. So, the combination of the HWC method and GT, which is feasible, improves the strength of the cement mortar.

These curing methods could be applied when posttension construction member is made on-site, especially combined curing that is standard curing first and then hotwater curing. Standard curing allows the member to reach certain strength, and then hot-water curing allows the member to quickly reach design strength. Such two-stage curing reduces the prestress loss of the member because reinforcement and concrete become a whole as a result of concrete reaching certain strength. These curing methods could still be used in prefabricated and prestressed members in the factory.

It is worth noting that the service environment of the building materials in a cold area or coastal areas involves salt or freeze-thaw or coupling state, so the influence of the GT and curing methods on the early durability of cement-based materials needs further analysis to prepare early construction materials with synergistic development of mechanical properties and durability.

\section{Conclusions}

This paper investigated the comprehensive properties and material characterization of GTCM during the combined effect of GT and curing methods, and the following conclusions were drawn:

(1) The combined effect of the GT and HWC method increased the flexural strength and compressive strength of cement mortar which has an important impact on special engineering and rapid repair of structures.

(2) The combined effect of the GT and HWC method improved the material characteristics of the cementbased materials at the early stage and provided substantial benefits, especially regarding the amount of hydration products, such as $\mathrm{CH}$ and high-density
C-S-H gel, the pore structure distribution, and the content of the main functional groups.

(3) The comprehensive influence mechanism of the GT and HWC methods was illustrated in the presented model, and the optimal GT incorporation and optimal curing methods were quantitatively analyzed by the constructed equation. In summary, the results show that when the GT level is $20 \%$ and the HWC method is used, cement-based materials with excellent early performance can be prepared.

\section{Data Availability}

The data used to support the findings of this study are available from the corresponding author upon request.

\section{Disclosure}

Hongbo Liu and Ben Li are the co-first authors.

\section{Conflicts of Interest}

The authors declare no conflicts of interest.

\section{Authors' Contributions}

Hongbo Liu and Ben Li contributed equally to this work.

\section{Acknowledgments}

The authors accept the financial support provided by the National Natural Science Foundation of China (51678221) and the Heilongiiang Natural Science Foundation (LC2017025).

\section{References}

[1] N. H. Parameshwar and S. C. Yaragal, "Effect of different curing regimes and durations on early strength development of reactive powder concrete," Construction and Building Materials, vol. 154, pp. 72-87, 2017.

[2] A. A. Mokhtar, R. Belarbi, F. B. Jema, N. Burlion, and B. Capra, "Experimental investigation of the variability of concrete durability properties," Cement \& Concrete Research, vol. 1, no. 25, pp. 21-36, 2013.

[3] Y. Guo, Z. Chen, X. Qin, A. Shen, S. Zhou, and Z. Lyu, "Evolution mechanism of microscopic pores in pavement concrete under multi-field coupling," Construction and Building Materials, vol. 173, pp. 381-393, 2018.

[4] A.-A. Gahtani, "Effect of curing methods on the properties of plain and blended cement concretes," Construction and Building Materials, vol. 24, no. 3, pp. 308-314, 2010.

[5] M. Ibrahim, M. Shameem, M. Al-Mehthel, and M. Maslehuddin, "Effect of curing methods on strength and durability of concrete under hot weather conditions," Cement and Concrete Composites, vol. 41, pp. 60-69, 2013.

[6] H. Hani, N. Husam, and S. Nakin, "Effect of pozzolanic materials and curing methods on the elastic modulus of HPC," Cement and Concrete Composites, vol. 27, no. 6, pp. 661-670, 2005.

[7] P. Ghoddousi and L. Adelzade Saadabadi, "Study on hydration products by electrical resistivity for self-compacting 
concrete with silica fume and metakaolin," Construction and Building Materials, vol. 154, pp. 219-228, 2017.

[8] H.-J. Chen, S.-S. Huang, C.-W. Tang, M. A. Malek, and L.-W. Ean, "Effect of curing environments on strength, porosity and chloride ingress resistance of blast furnace slag cement concretes: a construction site study," Construction and Building Materials, vol. 35, pp. 1063-1070, 2012.

[9] T. Uygunoğlu and I. Hocaoğlu, "Effect of electrical curing application on setting time of concrete with different stress intensity," Construction and Building Materials, vol. 162, pp. 298-305, 2018.

[10] D. P. Bentz, S. Z. Jones, and K. A. Snyder, "Design and performance of ternary blend high-volume fly ash concretes of moderate slump," Construction and Building Materials, vol. 84, pp. 409-415, 2015.

[11] L. Xiao and Z. Li, "Early-age hydration of fresh concrete monitored by non-contact electrical resistivity measurement," Cement and Concrete Research, vol. 38, no. 3, pp. 312-319, 2008.

[12] X. Wei, L. Xiao, and Z. Li, "Prediction of standard compressive strength of cement by the electrical resistivity measurement," Construction and Building Materials, vol. 31, pp. 341-346, 2012.

[13] A. Boukhelkhal, L. Azzouz, S. Kenai, E.-H. Kadri, and B. Benabed, "Combined effects of mineral additions and curing conditions on strength and durability of self-compacting mortars exposed to aggressive solutions in the natural hot-dry climate in North African desert region," Construction and Building Materials, vol. 197, pp. 307-318, 2019.

[14] M. Nasir, O. S. B. Al-Amoudi, H. J. Al-Gahtani, and M. Maslehuddin, "Effect of casting temperature on strength and density of plain and blended cement concretes prepared and cured under hot weather conditions," Construction and Building Materials, vol. 112, pp. 529-537, 2016.

[15] M. I. Khan and Y. M. Abbas, "Curing optimization for strength and durability of silica fume and fuel ash concretes under hot weather conditions," Construction and Building Materials, vol. 157, pp. 1092-1105, 2017.

[16] O. Çakır and F. Aköz, "Effect of curing conditions on the mortars with and without GGBFS," Construction and Building Materials, vol. 22, pp. 308-314, 2008.

[17] W. Yahiaoui, S. Kenai, B. Menadi, and E. H. Kadri, "Durability of self-compacted concrete containing slag in hot climate," Advances in Concrete Construction, vol. 5, no. 3, pp. 271-288, 2017.

[18] D. M. Sadek, M. M. El-Attar, and H. A. Ali, "Reusing of marble and granite powders in self-compacting concrete for sustainable development," Journal of Cleaner Production, vol. 121, pp. 19-32, 2016.

[19] O. Oueslati and J. Duchesne, "The effect of SCMs and curing time on resistance of mortars subjected to organic acids," Cement and Concrete Research, vol. 42, no. 1, pp. 205-214, 2012.

[20] Q. Li, X. Huang, Z. Huang, and G. Yuan, "Bond characteristics between early aged fly ash concrete and reinforcing steel bar after fire," Construction and Building Materials, vol. 147, pp. 701-712, 2017.

[21] T. F. Kamile, E. Godek, M. Keskinates, and B. Felekoglu, "Utilization and selection of proper fly ash in cost effective green HTPPECC design," Journal of Cleaner Production, vol. 149, pp. 557-568, 2017.

[22] Z. Liu, D.-w. Zhang, L. Li, J.-x. Wang, N.-n. Shao, and D.-m. Wang, "Microstructure and phase evolution of alkaliactivated steel slag during early age," Construction and Building Materials, vol. 204, pp. 158-165, 2019.
[23] Y. Guo, J. Xie, J. Zhao, and K. Zuo, "Utilization of unprocessed steel slag as fine aggregate in normal- and highstrength concrete," Construction and Building Materials, vol. 204, pp. 41-49, 2019.

[24] J. Zhao, P. Yan, and D. Wang, "Research on mineral characteristics of converter steel slag and its comprehensive utilization of internal and external recycle," Journal of Cleaner Production, vol. 156, pp. 50-61, 2017.

[25] Y. Guo, J. Xie, W. Zheng, and J. Li, "Effects of steel slag as fine aggregate on static and impact behaviours of concrete," Construction and Building Materials, vol. 192, pp. 194-201, 2018.

[26] L. Feng, P. Zhao, Z. Wang, J. Gao, X. Su, and H. Li, "Improvement of mechanical properties and chloride ion penetration resistance of cement pastes with the addition of predispersed silica fume," Construction and Building Materials, vol. 182, pp. 483-492, 2018.

[27] F. Han, S. Song, J. Liu, and S. Huang, "Properties of steamcured precast concrete containing iron tailing powder," Powder Technology, vol. 345, pp. 292-299, 2019.

[28] C. Yunhong, H. Fei, L. Wenchuan, L. Rui, L. Guanglu, and W. Jingming, "Test research on the effects of mechanochemically activated iron tailings on the compressive strength of concrete," Construction and Building Materials, vol. 118, pp. 164-170, 2016.

[29] A. Rajasekar, K. Arunachalam, and M. Kottaisamy, "Assessment of strength and durability characteristics of copper slag incorporated ultra high strength concrete," Journal of Cleaner Production, vol. 208, pp. 402-414, 2019.

[30] A. R. Lori, A. Hassani, and R. Sedghi, "Investigating the mechanical and hydraulic characteristics of pervious concrete containing copper slag as coarse aggregate," Construction and Building Materials, vol. 197, pp. 130-142, 2019.

[31] H. Liu, K. Liu, Z. Lan, and D. Zhang, "Mechanical and electrical characteristics of graphite tailing concrete," Advances in Materials Science and Engineering, vol. 2018, Article ID 9297628, 9 pages, 2018.

[32] P. Kathirvel, S.-J. Kwon, H.-S. Lee, S. Karthick, and V. Saraswathy, "Graphite ore tailings as partial replacement of sand in concrete," ACI Materials Journal, vol. 115, pp. 481492, 2018.

[33] GB/T 17671-1999, Cement Mortar Strength Test Method, ISO, Geneva, Switzerland, 1999.

[34] J. M. Khatib and P. S. Mangat, "Influence of high-temperature and low-humidity curing on chloride penetration in blended cement concrete," Cement and Concrete Research, vol. 32, no. 11 , pp. $1743-1753,2002$.

[35] A. Bertron, J. Duchesne, and G. Escadeillas, "Accelerated tests of hardened cement pastes alteration by organic acids: analysis of the pH effect," Cement and Concrete Research, vol. 35, no. 1, pp. 155-166, 2005.

[36] JTG E30-2005, Test Method of Cement and Concrete for Highway Engineering, China Communications Press, Beijing, China, 2005.

[37] GB/T 21650-2008, Pore Size Distribution and Porosity of Solid Materials by Mercury Porosimetry and Gas adsorption. Part 1: Mercury Porosimetry, ISO, Geneva, Switzerland, 2008.

[38] GB/T 16594-2008, General Rules for Measurement of Length in Micron Scale by SEM, ISO, Geneva, Switzerland, 2008.

[39] GB/T 30904-2014, Inorganic Chemicals for Industrial Use: Crystal Form Analysis on X-Ray Diffraction Method, ISO, Geneva, Switzerland, 2014. 
[40] ISO 19618-2017, Measurement Method for Normal Spectral Emissivity Using Blackbody Reference with an FTIR Spectrometer, ISO, Geneva, Switzerland, 2017.

[41] J. W. Bullard, H. M. Jennings, R. A. Livingston et al., "Mechanisms of cement hydration," Cement and Concrete Research, vol. 41, no. 12, pp. 1208-1223, 2011.

[42] K. Scrivener and O. Alexandre, "Advances in understanding cement hydration mechanisms," Cement and Concrete Research, vol. 124, 2019. 